Polysynthesis in Hueyapan Nahuatl: The Status of Noun Phrases, Basic Word Order, and Other Concerns

Pharao Hansen, Magnus

Published in:

Anthropological Linguistics

Publication date:

2010

Citation for published version (APA):

Pharao Hansen, M. (2010). Polysynthesis in Hueyapan Nahuatl: The Status of Noun Phrases, Basic Word Order, and Other Concerns. Anthropological Linguistics, 52(3), 274. 


\section{PROJECT MUSE}

\section{Polysynthesis in Hueyapan Nahuatl: The Status of Noun Phrases, Basic Word Order, and Other Concerns}

Magnus Pharao Hansen

Anthropological Linguistics, Volume 52, Numbers 3-4, Fall and Winter 2010, pp. 274-299 (Article)

Published by University of Nebraska Press

DOI: 10.1353/anl.2010.0017

$\Rightarrow$ For additional information about this article

http://muse.jhu.edu/journals/anl/summary/v052/52.3-4.hansen.html 


\title{
Polysynthesis in Hueyapan Nahuatl: \\ The Status of Noun Phrases, Basic Word Order, and Other Concerns
}

\author{
MAGNus PHARAO HANSEN
}

Brown University

\begin{abstract}
This article presents data showing that the syntax of the Nahuatl dialect spoken in Hueyapan, Morelos, Mexico has traits of nonconfigurationality: free word order and free pro-drop, with predicate-initial word order being pragmatically neutral. It permits discontinuous noun phrases and has no naturally occurring true quantifiers, suggesting that noun phrases in Hueyapan Nahuatl are adjuncts rather than actual arguments. These findings are contrasted with those of an earlier study by Jeffrey MacSwan, who concludes that Nahuatl syntax has relatively fixed subject-verb-object word order. It is suggested that the differences observed between the two Nahuatl varieties may be a result of methodological problems in MacSwan's collection of data, skewing it in the direction of a more rigid syntax.
\end{abstract}

1. Introduction. This article examines data on the syntax of the Nahuatl dialect of Hueyapan, Morelos, Mexico. Hueyapan Nahuatl syntax is characterized by obligatory headmarking of all phrasal arguments on their phrasal heads, making the language an example of a polysynthetic language in the terminology of Mark C. Baker (1996). The syntax in a corpus of spoken Nahuatl gathered from sixteen consultants between the ages of fourteen and eighty-three shows traits of nonconfigurationality as predicted by Baker for polysynthetic languages. It has free, pragmatically determined, word order, with predicate-initial order being pragmatically unmarked. It allows pro-drop of all arguments of phrasal heads, and the construction of discontinuous noun phrases. The corpus also shows considerable syntactic variation that correlates with age and proficiency of speakers, with fewer nonconfigurational traits being found among younger speakers and among older speakers who are Spanish-dominant.

MacSwan (1998) uses data from Southeast Puebla Nahuatl to argue against Baker's proposal that there is a "Polysynthesis Parameter" (1996). MacSwan describes the syntax of the variety of Nahuatl that he studies as having relatively fixed subject-verb-object (SVO) word order, and not being "essentially different from the syntax of English, Spanish or other well-studied languages" (1998:103).

One would like to know why the findings about syntax in the Hueyapan data completely contradict MacSwan's findings from southeast Puebla. I conclude that, although the possibility that Southeast Puebla Nahuatl has fixed SVO word order cannot be excluded, MacSwan's data are not sufficiently extensive or of high enough quality to determine whether that is the case. In particular, the 
fact that MacSwan's data come from a small number of consultants from very similar social backgrounds who have been chosen for their high degree of bilingualism raises the question whether the data are representative of the larger speech community. Furthermore, the methodology used by MacSwan for data gathering was a combination of sentence judgment tasks by a few highly bilingual consultants and narratives written by consultants who do not normally write in Nahuatl, and this biases the data towards a high degree of influence from Spanish and towards a higher degree of "literate" as opposed to "oral" syntactic traits, in the terminology of Chafe (1982) and Foley (2002).

The principal aim of this article is not primarily to vindicate Baker's Polysynthesis Parameter, but to address methodological concerns in the description of Nahuatl syntax. As Mithun (2001) points out, researchers dealing with endangered languages should be aware of the need to deal responsibly with linguistic data, in order to avoid the introduction of "noise" into the linguistic documentation that will likely be the only source of knowledge about these languages for future generations.

1.1. Polysynthesis in Nahuatl. Nahuatl, particularly the colonial literary variety known as Classical Nahuatl, has often been cited as an example of a canonical polysynthetic language. The pretheoretical sense of the word "polysynthesis" applies to Nahuatl because the language is highly agglutinating and allows the possibility of forming "sentence words," single words that express the meaning of an entire English sentence. It also allows incorporation of objects and an array of adverbial elements into verbs, traits that have also traditionally been associated with polysynthesis (Launey 1999). But this pretheoretical understanding of polysynthesis does not constitute a definition allowing linguists to state unequivocally that a language is or is not polysynthetic. Rather, it is a question of the degree to which it conforms to a polysynthetic prototype.

Baker (1996) proposes a restrictive definition of polysynthesis that would allow some languages to be defined as polysynthetic, and other languages as merely having a high degree of morphological synthesis. Observing the cooccurrence of a number of syntactic peculiarities in a number of languages commonly described as nonconfigurational and polysynthetic, Baker proposes a polysynthetic macroparameter within the Principles and Parameters framework. In this way, Baker attempts to account for the particular syntactic and morphological traits of those languages by attributing them to a basic shared syntactic principle called the "Polysynthesis Parameter."

The parameter consists of a rule called the Movement Visibility Condition:

A phrase $\mathrm{X}$ is visible for $\theta$-role assignment from a head $\mathrm{Y}$ only if it is coindexed with a morpheme in the word containing $\mathrm{Y}$ via: (i) an agreement relationship, or (ii) a movement relationship. [Baker 1996:17] 
This rule can be paraphrased as follows: polysynthetic languages by definition require that every phrasal argument be marked on the head of which the phrase is an argument, and this marking can be achieved either by use of agreement morphemes or by incorporating the argument noun phrase into the head.

Baker further proposes that a number of secondary syntactic and morphological traits are secondary effects of these two rules and hence are shared by all the languages that adhere to the Polysynthesis Parameter. Among the suggested secondary traits of polysynthetic languages are the following:

- They are nonconfigurational (showing free word order, free pro-drop, discontinuous syntactic expressions, and extensive use of zero anaphora).

- Free noun phrases cannot occupy positions as arguments of phrases; their status instead is that of mere adjuncts. Arguments are instead incorporated into phrasal heads in the form of pronominal affixes.

- Since noun phrases are not arguments, they cannot be subject to certain kinds of external specification-e.g., quantification and determination.

- There are no verb forms that do not overtly select their arguments, e.g., infinitives.

Classical Nahuatl is one of the languages used by Baker as support for his proposed macroparameter; he argues it to have all the properties of a polysynthetic language under his definition. And indeed the language can be analyzed as having all or most of the properties that he ascribes to polysynthetic languages, something that has also been noted by Nahuatl grammarians such as Launey (1999:114).

However, Classical Nahuatl is but one of many dialects of Nahuatl, and it is known to have been an innovative dialect (Canger 1988), so it is possible that not all dialects of Nahuatl in precolonial times had these particular traits. Furthermore, under the influence of contact with Spanish the dialects spoken today have undergone a number of structural changes and may not have these polysynthetic traits any longer. Indeed, some scholars have suggested that modern varieties of Nahuatl have shifted their typological properties and can no longer be classified as polysynthetic in the non-Bakerian, pretheoretical sense of the word (Hill and Hill 1986; Flores Farfán 2001). This makes it relevant to study the degree of polysynthesis in modern varieties of Nahuatl, both in Bakerian and in more pretheoretical terms.

2. Data from Hueyapan. Hueyapan is a town in the northeastern corner of the state of Morelos in central Mexico, located on the southern slopes of Mt. Popocatepetl about 2,500-3,000 meters above sea level. It is the home of approximately 6,900 inhabitants of indigenous Nahua ethnicity. In Hueyapan, the Nahuatl language is severely endangered, since natural transmission ceased from about 1970; inhabitants born later than this are usually monolingual Spanish speakers or have only passive Nahuatl competence. 
2.1. Methods used for data collection in Hueyapan. My data from Hueyapan were gathered between February and May 2005 as part of an investigation of whether the language is in a process of shifting typology from a polysynthetic type to a more analytic one. The definition of polysynthesis applied was that of Baker (1996), not because I believe in the existence of a polysynthesis macroparameter, but rather because the description of polysynthesis as obligatory head-marking of all phrasal arguments seemed a useful description of the particular kind of polysynthesis found in Nahuatl.

Since the aim of the investigation was to determine whether a development was in progress, I strove to achieve the greatest possible age range for the consultants and the maximal level of comparability between the different texts. Furthermore, in order to accurately capture usage, it was necessary for the data to be naturally occurring speech. Achieving the maximal level of comparability while retaining a high degree of naturalness poses a dilemma. I opted for collecting narrative texts elicited in response to a visual stimulus. In order to obtain a high degree of comparability, both within the corpus and with data collected in other languages, I decided to use as stimulus Mercer Mayer's picture book Frog, Where Are You?, known to linguists as "The Frog Story" (Mayer 1969), since this has been used in many similar studies. In order to reduce my own possible contamination of the data, I preferred to have the stories told, not to me, but to another consultant, preferably one with a close relation to the narrator. This was not always possible in practice, but most of the stories gathered were told by consultants to other consultants.

I recorded thirty-five interviews, nineteen of which were discarded due to problems with quality - either because the consultant was unable, or unwilling, to use the picture material as basis for the interview or, for some of the younger semispeakers, because the ratio of Nahuatl to Spanish was too low. Several interviews were discarded simply because of poor recording quality. The sixteen selected interviews totaled 4.2 hours of recording and 2,478 phrases. The ages of the consultants ranged from fourteen to eighty-three. Of the sixteen consultants, five were men and eleven were women. The consultants came from two of Hueyapan's four neighborhoods and from two outlying colonias, which gave a reasonable spread between the most urbanized barrios and the more rural colonias. A schematic overview of the interviews is given in table 1.

Even though I sought to achieve a high degree of comparability in the recorded material, the types of texts produced showed considerable variation. The principal source of variation was the different narrators' personal styles of speaking and their understanding of the interview situation: some consultants produced coherent narratives with a beginning and an end and sometimes even a moral; other interviews turned out more as conversations about the pictures between two consultants; and another large group of consultants confined themselves to describe the contents of every picture in a fragmentary way without ever connecting them in an actual narrative. 
Table 1. List of Interviews and Narrators

\begin{tabular}{|c|c|c|c|c|}
\hline NAME & AGE & BARRIO (NEIGHBORHOOD) & DATE & LENGTH (MIN.) \\
\hline Rodrigo & 14 & Centro, Hueyapan & 04/05/2004 & $5: 46$ \\
\hline Saraí & 23 & Colonia El Olivar, Hueyapan & 09/03/2004 & $9: 28$ \\
\hline Reina & 25 & S. Andrés, Hueyapan & 02/03/2004 & $10: 19$ \\
\hline Catalina & 28 & S. Andrés, Hueyapan & 09/03/2004 & $18: 41$ \\
\hline Maribel & 31 & S. Andrés, Hueyapan & 29/01/2004 & $9: 40$ \\
\hline Minerva & 41 & Centro, Hueyapan & $13 / 02 / 2004$ & 12:01 \\
\hline Andres & 42 & Colonia El Olivar, Hueyapan & 09/03/2004 & 9:08 \\
\hline Enriqueta & 45 & Centro, Tepisillān, Hueyapan & $13 / 02 / 2004$ & $11: 06$ \\
\hline Christina & 46 & S. Andrés, Hueyapan & $27 / 02 / 2004$ & $16: 20$ \\
\hline Rosalio & 50 & S. Andrés, Hueyapan & $27 / 02 / 2004$ & 8:32 \\
\hline Epimenio & 50 & S. Andrés, Hueyapan & $07 / 02 / 2004$ & $15: 34$ \\
\hline Raquel & 54 & S. Andrés, Rancho Tenería, Hueyapan & 07/03/2004 & $13: 06$ \\
\hline Angelina & 55 & S. Andrés, Hueyapan & 07/02/2004 & 28:34 \\
\hline Abraham & 58 & S. Andrés, Rancho Tenería, Hueyapan & 07/03/2004 & $12: 18$ \\
\hline Larín & 74 & Centro, Hueyapan & $21 / 02 / 2004$ & $38: 44$ \\
\hline Ciro & 83 & S. Andrés, Rancho Tenería, Hueyapan & 28/02/2004 & $16: 30$ \\
\hline
\end{tabular}

This observation of coherence vs. fragmentation seems to correlate with Foley's (2002) observation that the Frog Story sometimes prompted a much more literate narrative style than would usually be adopted in more traditional oral narratives. The present study seems to confirm this, since the consultants whose narratives have the highest degree of narrative integration and personal detachment are also the ones that use literacy the most in their daily life. The most coherent narratives were formed by Saraí, Minerva, Don Andrés, and Don Abraham. Saraí and her father, Don Andrés, are Jehovah's Witnesses, and their religion demands a very high degree of literacy from its followers, who are expected to read up to three thousand pages of religious material per year. Minerva no longer lives in Hueyapan but in Mexico City; she is interested in literature and reads fiction and therapeutic literature in Spanish out of interest. Don Abraham is a local politician and has worked as a secretary in town administration in several periods. In contrast, the more fragmentary narratives also show a higher degree of personal involvement and are often conducted as conversations, with the narrators performing speech acts such as posing questions or giving opinions, using "aside" comments, and generally involving their audience. Although most of the other consultants know how to read Spanish (except Rodrigo), they do not engage in reading for its own sake but only when they are required to, e.g., when doing official paperwork, etc. This then, suggests that even if the sample is only composed of Frog Stories, it manages to capture both features of literate and oral narratives.

The length of the interviews also varied with the enthusiasm of the narrator-for some interviews I ended up having to cut out lengthy digressions where 
the narrator went into explanations or conversations that were not based in the pictures. All of the interviews were transcribed with the help of native-speaking consultants who have approved the transcribed phrases as both grammatical and as containing what the narrators actually say.

2.2. Pro-drop. One set of questions that I investigated in the interview data was whether the syntax presented traits of nonconfigurationality, since Baker defines this as an important implication of polysynthesis in his sense. Classic nonconfigurationality is defined as a syntax characterized by the combination of free word order with free pro-drop (and the consequent use of zero anaphora) of all direct arguments of a phrasal head-i.e., that noun phrase arguments of phrasal heads are optional, and if they occur, their order is not subject to grammatical restrictions. Often languages defined as nonconfigurational use word order to mark pragmatic relations such as focus and topic (Golumbia 2004).

The first statistical analysis I conducted related the total number of sentences to the number of sentences in which a subject or an object was a free noun phrase. The number of sentences with a subject as a free constituent and their ratio to the total number of sentences is given in table 2 . The number of sentences with an object as a free constituent and their ratio to the total number of transitive sentences is given in table 3 .

\section{Table 2. Proportion of Sentences with Subject as a Free Noun Phrase}

\begin{tabular}{lrrrr}
\hline NARRATOR & AGE & SENTENCES & $\begin{array}{c}\text { SENTENCES WITH SUBJECT AS } \\
\text { AS A FREE NP }\end{array}$ & PERCENTAGE \\
Rodrigo & 14 & 122 & 46 & \\
Saraí & 23 & 101 & 32 & 37.7 \\
Reina & 25 & 82 & 39 & 31.7 \\
Catalina & 28 & 131 & 18 & 47.5 \\
Maribel & 31 & 73 & 17 & 13.7 \\
Minerva & 41 & 111 & 37 & 23.2 \\
Andres & 42 & 122 & 46 & 33.3 \\
Enriqueta & 45 & 153 & 61 & 37.7 \\
Christina & 46 & 149 & 49 & 39.9 \\
Rosalio & 50 & 120 & 43 & 32.8 \\
Epimenio & 50 & 190 & 106 & 35.8 \\
Raquel & 54 & 141 & 118 & 22.0 \\
Angelina & 55 & 337 & 46 & 35.0 \\
Abraham & 58 & 129 & 181 & 35.6 \\
Larín & 74 & 326 & 51 & 35.5 \\
Ciro & 83 & 131 & 921 & 37.2 \\
Total & & 2,478 & & \\
\hline
\end{tabular}


Table 3. Proportion of Transitive Sentences with Object as a Free Noun Phrase

\begin{tabular}{lcccc}
\hline NARRATOR & AGE & $\begin{array}{c}\text { TRANSITIVE } \\
\text { SENTENCES }\end{array}$ & $\begin{array}{c}\text { SENTENCES WITH OBJECT } \\
\text { AS A FREE NP }\end{array}$ & PERCENTAGE \\
Rodrigo & 14 & 57 & 37 & 64.9 \\
Saraí & 23 & 58 & 29 & 50.0 \\
Reina & 25 & 37 & 18 & 48.6 \\
Catalina & 28 & 52 & 11 & 21.1 \\
Maribel & 31 & 38 & 13 & 34.2 \\
Minerva & 41 & 50 & 21 & 42.0 \\
Andres & 42 & 74 & 27 & 36.5 \\
Enriqueta & 45 & 60 & 21 & 35.0 \\
Christina & 46 & 61 & 37 & 60.7 \\
Rosalio & 50 & 54 & 14 & 25.9 \\
Epimenio & 50 & 43 & 32 & 60.5 \\
Raquel & 54 & 72 & 79 & 44.4 \\
Angelina & 55 & 175 & 33 & 82.5 \\
Abraham & 58 & 40 & 82 & 45.8 \\
Larín & 74 & 179 & 19 & 37.2 \\
Ciro & 83 & 51 & 499 & 45.3 \\
Total & & 1,101 & & \\
\hline
\end{tabular}

In 62.8 percent of sentences in the analyzed corpus, the subject does not appear as a free constituent. However, significant deviance from that average is found among the four youngest speakers. The smallest percentage of free subject noun phrases is found in Catalina's narrative, in which free noun phrases appear as subject in only 13.7 percent of the sentences. This is likely caused by the fact that she is a Spanish-dominant bilingual and by her narrative style, which is very closely bound to the pictorial stimulus. Most of her sentences consist in pointing out an element in the picture and stating "this is X," and, accordingly, a large number of sentences include only a predicate. The interviews of the three speakers younger than Catalina show higher percentages of subjects as free constituents, but their interviews are short, with between 82 and 122 total sentences. It is reasonable to assume that a smaller number of sentences results in more free constituents in order to able to build a coherent narrative.

The statistics also show that it is not necessary for the object to be a free constituent noun phrase: 54.7 percent of transitive sentences do not have the object as a free constituent (see table 3). It is not possible to correlate the degree to which objects occur as free constituents with either age or narrative style. It is likely that it correlates with pragmatic factors such as topicality, but this has not been investigated.

2.3. Word order. Another element of nonconfigurationality is free word order, by which is meant that the order of free phrasal constituents is not fixed by grammatical restrictions. The statistical analysis of sentences with at least one free constituent shows that the relative order of sentence constituents in 
Hueyapan Nahuatl is not grammatically determined. Furthermore, analysis shows that information structure is the principal factor determining the position of noun phrases relative to the phrasal head. The pragmatically unmarked constituent order is predicate-initial, with constituents being fronted to the beginning of a sentence in topic and focus constructions. As is seen in table 4, which summarizes the analysis of sentences with at least one free constituent other than the predicate, all word orders except OSV occur in the corpus. (As is usual in studies of word order typology, "O," "S," and "V" abbreviate "subject," "object," and "verb." $)$ Orders with an initial verb (VO, VS, VSO, VOS) constitute 64.3 percent of all sentences, orders with an initial subject (SV, SVO, SOV) constitute 33.2 percent of sentences, and sequences with an initial object (OV, OVS) constitute 2.5 percent of all sentences. The absence of OSV need not imply that this sequence is ungrammatical, but may be a result of the limited amount of phrases analyzed. Examples (1)-(9) show the different types of word order occurring in the data. ${ }^{2}$

Table 4. Order of Constituents

\begin{tabular}{|c|c|c|c|c|c|c|c|}
\hline NARRATOR & AGE & $\begin{array}{l}\text { SENTENCES WITH AT } \\
\text { LEAST ONE FREE } \\
\text { NP }\end{array}$ & $\begin{array}{l}\text { PRE } \\
\text { FIRS } \\
\text { VSC }\end{array}$ & $\begin{array}{l}\text { JICATE } \\
\text { Г (VS, VO, } \\
\text {, VOS) }\end{array}$ & $\begin{array}{l}\text { SUB } \\
\text { FIRS } \\
\text { SVC }\end{array}$ & $\begin{array}{l}\text { JECT } \\
\text { OT (SV, }\end{array}$ & $\begin{array}{l}\text { OBJECT } \\
\text { FIRST (OV, } \\
\text { OVS, OSV) }\end{array}$ \\
\hline Rodrigo & 14 & 76 & 46 & $(60.5 \%)$ & 27 & $(35.5 \%)$ & $3(3.9 \%)$ \\
\hline Saraí & 23 & 57 & 30 & $(52.6 \%)$ & 27 & (47.4\%) & 0 \\
\hline Reina & 25 & 53 & 28 & $(52.8 \%)$ & 24 & $(45.2 \%)$ & $1(1.9 \%)$ \\
\hline Catalina & 28 & 29 & 23 & (79.3\%) & 6 & $(20.7 \%)$ & 0 \\
\hline Maribel & 31 & 27 & 18 & $(66.6 \%)$ & 9 & $(33.3 \%)$ & 0 \\
\hline Minerva & 41 & 58 & 38 & $(65.5 \%)$ & 20 & (34.5\%) & 0 \\
\hline Andres & 42 & 67 & 48 & $(71.6 \%)$ & 18 & $(26.9 \%)$ & $1(1.5 \%)$ \\
\hline Enriqueta & 45 & 68 & 37 & (54.4\%) & 31 & $(45.6 \%)$ & 0 \\
\hline Christina & 46 & 77 & 45 & (58.4\%) & 27 & $(35.0 \%)$ & $5(6.5 \%)$ \\
\hline Rosalio & 50 & 57 & 31 & $(54.4 \%)$ & 25 & $(43.8 \%)$ & $1(1.7 \%)$ \\
\hline Epimenio & 50 & 116 & 83 & $(71.1 \%)$ & 32 & $(27.6 \%)$ & $1(0.9 \%)$ \\
\hline Raquel & 54 & 57 & 35 & (61.4\%) & 21 & $(36.8 \%)$ & $1(1.7 \%)$ \\
\hline Angelina & 55 & 179 & 113 & $(64.5 \%)$ & 58 & $(32.4 \%)$ & $8(4.5 \%)$ \\
\hline Abraham & 58 & 75 & 55 & $(73.3 \%)$ & 19 & $(25.3 \%)$ & $1(1.3 \%)$ \\
\hline Larín & 74 & 212 & 125 & (58.9\%) & 77 & $(36.3 \%)$ & $10(4.7 \%)$ \\
\hline Ciro & 83 & 59 & 29 & (49.1\%) & 27 & $(45.8 \%)$ & $3(5.0 \%)$ \\
\hline Total & & 1,351 & 869 & $(64.3 \%)$ & 448 & $(33.2 \%)$ & $34(2.5 \%)$ \\
\hline
\end{tabular}

(1) [the deer runs towards a ridge with the boy and dog on its antlers]

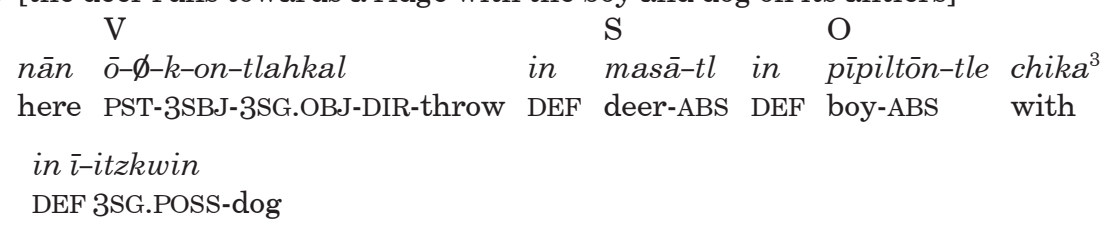

'Here the deer has thrown the boy as well as his dog.' 
(2) [the boy is picked up by the deer]

$\begin{array}{clll} & \mathrm{V} & \mathrm{O} & \mathrm{S} \\ \text { ihkion } & \emptyset \text {-ki-wīka } & \text { in } & \text { piltōnkone-tl in } \\ \text { masā-tl }\end{array}$

like.this 3SBJ-3SG.OBJ-carry DEF boy.child-ABS DEF deer-ABS

'The deer carries the boy-child in this way.'

(3) [the boy picks up his puppy]

\begin{tabular}{lllll}
\multicolumn{1}{r}{$\mathrm{S}$} & $\mathrm{V}$ & & $\mathrm{O}$ \\
in & chichikone--tl & $\bar{o}-\emptyset-k i-p a h p a l o-h$ & in & pipiltōn-tle \\
DEF & puppy-ABS & PST-3SBJ-3SG.OBJ-lick-PRF & DEF boy-ABS
\end{tabular}

'The puppy licks the boy.'

(4) [talking about the boy]

$\begin{array}{llll} & \mathrm{S} & \mathrm{O} & \mathrm{V} \\ \text { in } & \text { itzkwin } & \text { itla } & \emptyset \text {-ki-piya } \\ \text { DEF } & \text { dog } & \text { something } & \text { 3SBJ-3SG.OBJ-has }\end{array}$

'The dog has something.'

(5) [introducing the frogs]
O V
nān se $y-\bar{o}-\emptyset-k-a h s i-k$
$\mathrm{S}$
here one PFT-PST-3SBJ-3SG.OBJ-reach-PRF DEF boy-ABS
'Here the boy has caught one.'

(6) [talking about the boy]

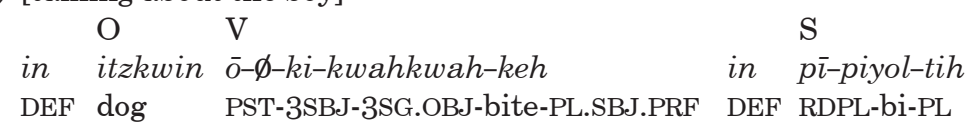

'The bees have stung the dog.'

Examples also occur in which a participant that is neither a subject nor an object, such as the location in (7) or the possessor in (8), is in fronted position, but these have not been analyzed statistically.

(7) [the boy is grabbing the deer's antlers]
LOC $\mathrm{V}$
in masā-tl $y-\bar{o}-\emptyset-m o-p i l o-h$
LOC
DEF deer-ABS PFT-PST-3SBJ-REFL.OBJ-hang-PRF 3SG.POSS-on
'The deer $\mathrm{i}_{\mathrm{i}}$, he has hung himself from it $\mathrm{i}_{\mathrm{i}}$ '

(8) [the boy is getting dressed]
POSSESSOR V
$\bar{a} n \bar{l}$-itzkwin $\bar{o}$-Ø-kalak-tok in $\bar{l}$-tzontegon
and 3SG.POSS-dog PST-3SBJ-enter-STAT DEF 3SG.POSS-head
LOC
ì-pān tewilō-tl
3SG.POSS-in jar-ABS
'And his dog's head is stuck in the jar.' 
The analysis of the patterns of presence vs. absence of subject and object as free constituents and the relative order of constituents showed that pragmatic factors were the principal determiner. New participants and participants with low topicality are usually introduced following the predicate. Fronted arguments are usually preceded by the particle in, which functions as a definite article, showing that the fronted argument is known information (see examples (3), (4), and (6)). Fronted position establishes an already-known participant as the topic of the following sentences, in which that participant can be referred to by null anaphora, as in (3)-(9). An analysis of the sentences in which the fronted participant is not the subject of the phrase shows that the fronted participant has a salient function in the information structure of the sentence; often it is the logical subject of the sentence, that is, the participant whom the sentence is about, and with whom the listener identifies (Lambrecht 1994:118). This function not only holds for fronted objects, but also for other functions such as possessors, locations, and indirect objects when these are in fronted position, as is shown in (6)-(8). ${ }^{4}$ This means that when a participant occurs in fronted position it is because it is the topic of the clause and the following clauses. Fronted position then correlates with the pragmatic status of a topic.

However, exceptions to these generalizations occur, in which a fronted element is unknown information and is preceded by the numeral se 'one' in its function as indefinite article. In these cases, the fronted element is usually emphasized by being set off from the rest of the sentence by intonation. This emphasis usually occurs in relation to a surprising or particularly important event in which the fronted participant has the most unexpected role. Pronouns such as yehwa or the short form yeh 'he, she, it' also tend to occur in fronted position, often accompanied by pointing out the relevant participant in the picture, or by an intonation shift in order to disambiguate between two or more third person singular participants. This kind of fronting corresponds to the pragmatic status of focus.

2.4. Possessive noun phrases. I also analyzed two kinds of possessive phrases, trying to determine whether the possessed expression always agreed with the possessor and whether heads of possessive noun phrases can also drop their arguments. In Nahuatl, possession is expressed by placing a prefix agreeing with the person and number of the possessor on the possessed entity, the head of the possessive phrase. One kind of possessive phrase is that which expresses ownership or part-whole relations, as in (9a). The other kind of possessive phrase is the locative phrase, which in Nahuatl is expressed by a possessive noun phrase-one of the so-called relational nouns occurs as the head of a possessive noun phrase while its argument is the possessor, as in (9b).

(9a) $\bar{i}$-kal Pedro

3POss-house Pedro

'Pedro's house' 
(9b) $\bar{\imath}$-pan te-tl

3POSS-on stone-ABS

'on the stone'

I found that in 95.2 percent of ownership phrases the possessor did not occur as a free constituent (see table 5). Furthermore, I found that the relative order of possessor and possessed was not determined by grammatical rules; both orders occur with comparable frequency (see table 6).

Table 5. Occurrence of Possessor NP in Ownership Possessive Phrases

\begin{tabular}{lccc}
\hline NARRATOR & AGE & $\begin{array}{c}\text { PossESSIVE PHRASES } \\
\text { WITHOUT POSSESSOR NP }\end{array}$ & $\begin{array}{c}\text { POSSESSIVE PHRASES } \\
\text { WITH POSSESSOR AS FREE NP }\end{array}$ \\
Rodrigo & 14 & 12 & 2 \\
Saraí & 23 & 15 & 0 \\
Reina & 25 & 6 & 0 \\
Catalina & 28 & 12 & 0 \\
Maribel & 31 & 4 & 0 \\
Minerva & 41 & 19 & 3 \\
Andres & 42 & 19 & 0 \\
Enriqueta & 45 & 20 & 0 \\
Christina & 46 & 12 & 3 \\
Rosalio & 50 & 4 & 2 \\
Epimenio & 50 & 32 & 0 \\
Raquel & 54 & 18 & 0 \\
Angelina & 55 & 15 & 1 \\
Abraham & 58 & 23 & 0 \\
Larín & 74 & 53 & 3 \\
Ciro & 83 & 17 & 1 \\
Total & & $281(95.2 \%)$ & 14 (4.7\%) \\
\hline
\end{tabular}

Table 6. Order of Possessor and Possessed in Ownership Possessive Phrases

$\begin{array}{lcccr}\text { NARRAtor } & \text { AGE } & \begin{array}{l}\text { Possessive PHRASES } \\ \text { WITH POSSESSOR AS } \\ \text { FREE NP }\end{array} & \begin{array}{c}\text { FREE POSSESSOR } \\ \text { PRECEDES HEAD }\end{array} & \begin{array}{c}\text { FREE POS } \\ \text { FOLLOWS }\end{array} \\ \text { Rodrigo } & 14 & 2 & 0 & 2 \\ \text { Saraí } & 23 & 0 & 0 & 0 \\ \text { Reina } & 25 & 0 & 0 & 0 \\ \text { Catalina } & 28 & 0 & 0 & 0 \\ \text { Maribel } & 31 & 0 & 0 & 0 \\ \text { Minerva } & 41 & 3 & 2 & 1 \\ \text { Andres } & 42 & 0 & 0 & 0 \\ \text { Enriqueta } & 45 & 0 & 0 & 0 \\ \text { Christina } & 46 & 3 & 1 & 1 \\ \text { Rosalio } & 50 & 2 & 0 & 0 \\ \text { Epimenio } & 50 & 0 & 0 & 1 \\ \text { Raquel } & 54 & 0 & 0 & 0 \\ \text { Angelina } & 55 & 1 & & \end{array}$




$\begin{array}{lrrrr}\text { Abraham } & 58 & 0 & 0 & 0 \\ \text { Larín } & 74 & 3 & 1 & 2 \\ \text { Ciro } & 83 & 1 & 0 & 1 \\ \text { Total } & & 14 & 5 & 9\end{array}$

Relational nouns always occur possessed ${ }^{5}$ and therefore I tried to determine whether they can occur without a free noun phrase as an argument, and whether they were used prepositionally, i.e., if they always occurred immediately before the argument they governed. I found that in the great majority of relational noun phrases, the relational noun immediately precedes an argument noun phrase (see table 7).

Table 7. Syntax of Relational Nouns

\begin{tabular}{lccc}
\hline NARRATOR & AGE & $\begin{array}{l}\text { RELATIONAL NOUN } \\
\text { HAS NO NP ARGUMENT OR } \\
\text { IS SEPARATED FROM ARGUMENT }\end{array}$ & $\begin{array}{l}\text { RELATIONAL NOUN } \\
\text { IMMEDIATELY }\end{array}$ \\
PRECEDES ARGUMENT \\
Rodrigo & 14 & 3 & 13 \\
Saraí & 23 & 0 & 11 \\
Reina & 25 & 0 & 11 \\
Catalina & 28 & 0 & 8 \\
Maribel & 31 & 1 & 10 \\
Minerva & 41 & 0 & 24 \\
Andres & 42 & 0 & 22 \\
Enriqueta & 45 & 3 & 21 \\
Christina & 46 & 5 & 32 \\
Rosalio & 50 & 0 & 14 \\
Epimenio & 50 & 10 & 27 \\
Raquel & 54 & 2 & 13 \\
Angelina & 55 & 9 & 36 \\
Abraham & 58 & 0 & 24 \\
Larín & 74 & 12 & 39 \\
Ciro & 83 & 2 & 8 \\
Total & & $47(13.05 \%)$ & 313 (86.95\%) \\
\hline
\end{tabular}

The discrepancy in the degree to which free argument noun phrases occur in the two kinds of possessive phrases can be explained by their different functions in the information structure of the sentences to which they belong. The function of possessive phrases is to connect two entities to each other in order to contribute new information to the discourse. Defining an entity as being owned by something only makes sense if the possessor is already known to the listener; only rarely will it make sense to describe something as owned by a participant that has not been mentioned yet. The opposite is the case with locative phrases-it often makes sense to describe the location of an entity in relation to something that is new. Otherwise, describing the location would not contribute new information to the discourse. In short, it is primarily discourse-pragmatic 
considerations that determine whether the possessor is represented by a free noun phrase or not. This can further be seen by comparing the two phrases with relational nouns in (10) and (11). In (11), the boy has been the topic of the last few sentences and the new information is his new location. The relational noun occurs immediately before the new participant, the rock, which functions as the location. But in (12), where the boy has also been topic of the preceding sentences, he can function as location for the action of the new participant, the animals (bees), without occurring as a free constituent.

(10) an nān yi $\emptyset$-tlehko $\emptyset$-pan se te-tl

and here now 3SBJ-climb.up 3POSS-on a rock-ABS

'And here he climbs up on a rock.'

(11) [the boy is crying ]

pos xi-k-itta in yolkā-meh. yi yīweh ì-pan

well IMP-3OBJ-see DEF animal-PL now go-PL 3POSS-on

'Well, look at the animals. Now they are on him.'

2.5. Status of noun phrases. Free pro-drop and free word order are essential traits when trying to show that a language has nonconfigurational properties. Another argument for nonconfigurationality is to show that the free-standing noun phrases do not occupy an argument position in the phrase structure but rather are adjuncts functioning as specifiers of the actual arguments-the agreement morphemes on the phrasal head.

One way to show that noun phrases have the syntactic status of adjuncts is to show that syntactically discontinuous noun phrases are possible-i.e., that constituents of noun phrases can be separated by elements that are not part of the noun phrase. My corpus contains a few such discontinuous noun phrases. In three of these, the quantifier or demonstrative (nochi 'all' in (12), in-om-meh 'these' in (13), se 'one' in (14)) that modifies a noun precedes the verb, but the noun itself follows the verb.

(12) nochi $y$-ō- $\emptyset-k i h-k \bar{\imath} s-k e h \quad$ in pi-piyol-tih

all PRF-PST-3SBJ-RDPL-come.out-PL.SBJ.PRF DEF RDPL-bee-PL

'All the bees came out one after the other.'

(13) $\bar{a} n$ in-om-meh $y$-ō- $\emptyset$-kih-kīs-keh pi-piyol-tih and DEF-DIST-PL PRF-PST-3SBJ-RDPL-come.out-PL.SBJ.PRF RDPL-bee-PL

'And these bees came out one after the other.'

(14) tlachiya se $\emptyset$-ki-pachichīna in $\bar{\imath}-m \bar{a}-m a h p i l$

look.like one 3SBJ-3SG.OBJ-suck DEF 3.SG.POSS-DIM-finger

'It looks like he's sucking on one of his little fingers.' 
In (15), the verb is inflected for plurality of subject but the free constituent, the $\mathrm{dog}$, is singular, and the plural subject is understood to also include the topic, the dog's owner, who is only referred to by the agreement morphemes. This kind of discontinuous construction occurs several times in my material. ${ }^{6}$

(15) [The boy carries the dog out of the water. There is a big fallen tree...] an $\bar{l}$-itzkwin $\bar{o}-\varnothing$-tlehko-h-keh pan kwohtzonte-tl and 3SG.POSS-dog PST-3SBJ-climb.up-PRF-PL.SBJ on tree.trunk-ABS 'And his dog, they climbed up on the tree trunk.'

2.6. Quantifiers in Hueyapan Nahuatl. As shown in (12) and (14), Hueyapan Nahuatl quantifiers do not behave like true quantifiers because they can be separated from the noun they quantify. Likewise, numerals and quantifiers do not trigger obligatory agreement in number in the noun phrases they modify. Nor do noun phrases obligatorily agree in number with the pronominal prefix with which they are coreferential, suggesting that, as Baker predicts, they are in fact adjunct specifiers of the pronominal prefixes on the verb and not themselves arguments of the verb.

However, due to the impossibility of procuring negative evidence through texts, the lack of true quantifiers in my corpus does not necessarily mean that no such quantifiers exist in Hueyapan Nahuatl. The quantifier kada 'every, each' used by MacSwan to disprove the applicability of the Polysynthesis Parameter in the Nahuatl variety he studies does not appear in my corpus, but I have heard it during my two years of fieldwork, albeit not with any significant frequency. It tends to be used only in the set phrase kada se 'each one', always modified by a phrase initiated with the Spanish particle de, e.g., cada se de tehwan 'each one of us'.

2.7. Variation between speakers. There is considerable variation between speakers in the analyzed material. The difference seems to correlate mainly with speaker proficiency (and age, which is closely related to Nahuatl proficiency in Hueyapan) and narrative style. Most cases of higher or lower frequencies of the properties analyzed are found among the four youngest speakers in the survey. Among the youngest four speakers, Catalina is the speaker with the lowest occurrence of both objects and subjects as free noun phrases. This is due to her fragmentary narrative style, which makes extensive use of pointing and, as a result, contains many predicates without arguments. Among the four youngest speakers, Rodrigo is the only one to use free-standing relational nouns at all. He is also the only one of the four to be Nahuatl-dominant, having been raised monolingually by his grandmother. It seems that the other three younger speakers do not operate with a lexical class of relational nouns, but instead with a category of prepositions as in Spanish, likely a result of low Nahuatl proficiency and being Spanish dominant. Rodrigo is also the only one of the younger speakers to use the fronted position for objects more than once in his narrative. 
This suggests that object fronting is avoided by the less proficient speakers. The only examples of discontinuous noun phrases, which admittedly are few, appear in narratives from the eight oldest speakers.

One other consultant, Don Abraham, shows consistently abnormal values. He is the only speaker with a pronounced purist attitude towards the Nahuatl language. For example, he is the only consultant to construct ad hoc neologisms rather than use Spanish loanwords. He also corrected his speaking partner, Doña Raquél, who is a fully fluent, Nahuatl-dominant speaker, when she used Spanish loans in her narrative. Don Abraham uses more objects as free constituents than any of the other speakers in the older half. Don Abraham's narrative style is detached and integrated as would be expected from a highly literate speaker (Foley 2002).

Apart from this, among the older group of speakers there is only insignificant syntactic variation and it should be uncontroversial to conclude that Hueyapan Nahuatl as spoken by proficient speakers shows the general characteristics described in the remainder of sections 2.2-2.5. But it is worth noting that the traits of nonconfigurationality seem to disappear surprisingly fast among the less proficient speakers. The influence of Spanish in the Nahuatl syntax of less proficient speakers is remarkable, and if they were to pass the Nahuatl language on to their children it might very well be a variety of Nahuatl characterized by "relatively fixed SVO syntax," and that would not be "essentially different from Spanish or English or other well-studied languages.”

\subsection{Status of nonconfigurationality and polysynthesis in Hueyapan}

Nahuatl. The evidence cited above should be sufficient to demonstrate that the syntax of Hueyapan Nahuatl is best described as nonconfigurational, and that it is not at all similar to the syntax of Spanish or English. In contrast to these languages, Nahuatl word order is sensitive only to pragmatic considerations, and so is the choice between including or omitting free noun phrases referring to the arguments of phrasal heads. Furthermore, Hueyapan Nahuatl allows the usage of discontinuous noun phrases, which suggests that noun phrases occupy adjunct positions while the real arguments are the pronominal arguments affixed to phrasal heads, as predicted by Baker. There are also no indications that Hueyapan Nahuatl has naturally occurring "true quantifiers."

3. MacSwan's claims. MacSwan (1998) describes the syntax of a particular Nahuatl variety based on data gathered by himself in the field in southeast Puebla. The data were gathered for his 1997 doctoral dissertation about intrasentential codeswitching; the 1998 article is a reworked version of section 2.5.3 of his dissertation, in which he describes Nahuatl syntax in order to later be able to analyze codeswitching data syntactically. His purpose in the article is to use his syntactic data to argue against Baker's Polysynthesis Parameter. He does this by showing that in his data the basic rules of the parameter are obeyed, but 
that some of the secondary traits, described by Baker as following from the basic rule of the parameter, are not present. Importantly, he finds that the syntax in his data is not nonconfigurational, but shows a basic, fixed, SVO word order. His main argument against the Polysynthesis Parameter is the fact that he has been able to document what he interprets as an example of a true quantifier, thereby disproving the notion that noun phrases are adjuncts in the language.

3.1. Word order. MacSwan presents two arguments in favor of positing a fixed basic SVO word order in his material. The first argument is that sentencejudgment tasks given to his consultants show that they find sentences (16) and (17), with SVO and VSO order, respectively, to be more natural than (18), with SOV order, which is used only to indicate contrast or focus. And they find (19), with OVS order, to be completely ungrammatical.

(16) Ne ni-k-tlasojtla in Maria. I 1SG.SBJ-3SG.OBJ-love IN Maria 'I love Maria.' (MacSwan 1998:104)

(17) Ni-k-tlasojtla ne in Maria. 1SG.SBJ-3SG.OBJ-love I IN Maria 'I love Maria.' (MacSwan 1998:105)

(18) Ne in Maria ni-k-tlasojtla.

I IN Maria 1SG.SBJ-3SG.OBJ-love

'I love Maria.' (MacSwan 1998:105)

(19) *In Maria ni-k-tlasojtla ne.

IN Maria 1SG.SBJ-3SG.OBJ-love I

'I love Maria.' (MacSwan 1998:105)

MacSwan's second argument is statistical. His analysis of five texts written by his consultants shows that these texts include 264 phrases exhibiting the following word orders:

Vs occurred very frequently in these texts without an overt subject or object, making it difficult to detect a basic word order. However, subjects occurred with verbs in SV, SVO, VS and VSO constructions, preverbally nearly $90 \%$ of the time and postverbally only about $10 \%$ of the time. Objects never occurred before verbs in the texts I examined. When subject, verb and object were all overtly present, SVO occurred about $98 \%$ of the time and VSO about $2 \%$ of the time. [1998:105]

This leads him to conclude that these two arguments "provide strong evidence that Southeast Puebla Nahuatl is an SVO language which allows postverbal subjects and occasionally fronted objects for purposes of focus and contrast" (1998:105). He finds further support in the reports of fixed SVO word order in 
Nahuatl studies by Tuggy (1979), Brockway (1979), and Sischo (1979). The reports of a basic VSO word order found in Beller and Beller (1979), Launey (1992), and Hill and Hill (1986) are seen as evidence that "some varieties of Nahuatl do or did have VSO word order, or that further study will reconcile these apparent inconsistencies" (1998:107). But he maintains that "What is important for present purposes, however, is the observation that Nahuatl is reported to have relatively fixed word order in a good variety of sources" (1998:107).

3.2. Status of noun phrases. MacSwan's argument that noun phrases in his data are not adjuncts is based on that fact that he has been able to elicit examples containing a true quantifier of the 'every' type, namely, the originally Spanish quantifier cada, which occurs as a borrowed particle kada in his Nahuatl data. Furthermore, the syntactic properties of kada in those examples conform to what would be expected of a true quantifier, showing the "weak crossover effect.” Sentences (20)-(22) were judged as grammatical by his consultants, while (22) was considered ungrammatical.

(20) Kada tlaka-tl o-Ø-ki-pipitzo in i-siwa. each man-ABS PST-3SBJ-3SG.OBJ-kiss IN 3SG.POSS-wife

'Each man kissed his wife.' (MacSwan 1998:105)

(21) Ye Ø-ki-tlasojtla kada tlaka-tl.

(s)he 3SBJ-3SG.OBJ-love each man-ABS

'(S)he loves each man.' (MacSwan 1998:105)

(22) Kada ichpochtle $\emptyset$-ki-tlasojtla $n$-i-kni.

each girl 3SBJ-3SG.OBJ-love IN-3SG.POSS-brother

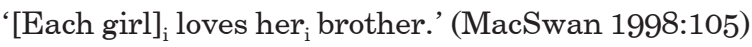

(23) ${ }^{*} N-i-k n i \quad \emptyset$-ki-tlasojtla kada ichpochtle.

IN-3SG.POSs-brother 3SBJ-3SG.OBJ-love each girl

'Her ${ }_{\mathrm{i}}$ brother loves [each girl] $]_{\mathrm{i}}$ ' (MacSwan 1998:105)

MacSwan concludes, "Since Southeast Puebla Nahuatl has true quantifiers (at least one), it cannot be true that NPs must be adjuncts in this language. I conclude that the basic clause structure of Nahuatl is not radically different from that of English or Spanish" (1998:110).

4. Reasons for the differences between Hueyapan and southeast Puebla. An explanation is required for the fact that MacSwan and the present author have drawn completely contradictory conclusions about the syntax of two closely related languages. A number of different parameters might be studied in order to understand the discrepancy. The differences could, for example, be 
dialectal, since the areas in which the material is gathered are several hundred kilometers apart.

In her description of Nahuatl dialect areas, Yolanda Lastra de Suárez (1986) defines the dialects of Morelos and southeast Puebla as both belonging to the group of Central dialects, the Morelos dialects belonging within the Nuclear subgroup while the dialects of southeast Puebla and the Zongolica area of Veracruz form their own subgroup. Lastra de Suárez's study is based only on phonological, lexical, and morphological criteria, and so it provides no evidence on whether syntactic differences such as those suggested by MacSwan's and my own data might exist within the dialect groups that she defines. However, as MacSwan points out, considerable syntactic differences have been reported in the literature on modern Nahuatl varieties. For example, the variety studied by myself and the Tetelcingo variety studied by David Tuggy (1979) are spoken within forty kilometers of each other, and yet Tetelcingo has fixed SVO word order, according to Tuggy. So even though the dialects of Hueyapan and southeast Puebla are closely related and highly mutually intelligible- they have a higher degree of mutual intelligibility with each other than, for example, with the dialect of Tetelcingo-considerable differences in word order between them must be considered a possibility.

However, looking at my own material one concern strikes me as obvious. Within Hueyapan, I have encountered considerable interspeaker syntactic variation, especially between the youngest, less fluent speakers and the rest of the group. The syntax of two of the three speakers who were not Nahuatl-dominant was much closer to a rigid SVO syntax than that of the older speakers (except for the purist Don Abraham, who also is Spanish-dominant) and thus much closer to MacSwan's findings. This suggests that a rigid syntax may well be conditioned by syntactic influence from Spanish, and it also suggests that it may be relevant to look at the kinds of data that MacSwan used in order to determine whether the fixed word order he reports is in fact a dialectal feature of Southeast Puebla Nahuatl as a whole, or could instead be explained by other factors.

MacSwan used two methods to obtain the data from which he determined word order in Southeast Puebla Nahuatl: grammaticality judgment tasks and analysis of texts written by his consultants. His dissertation (1997) includes other kinds of data such as naturally occurring codeswitching among children and adults. However, neither in the dissertation nor in the article discussed here does MacSwan appear to have drawn on that data for his conclusions about syntax. Rather, he appears to have used the sentence judgment tasks and analyses of written texts to arrive at a description of Nahuatl syntax that then served as a basis for the analysis of the more naturalistic codeswitching data.

Many scholars have concluded that grammaticality judgments of phrases composed by the linguist are not reliable enough to function as the principal evidence from which conclusions about linguistic form are to be drawn, and that naturalistic data are much to be preferred (Schütze 1996; Dimmendaal 2001; 
Mithun 2001; Harris and Voegelin 1953; Labov 1972). Even those who do find grammaticality judgments to be a useful source of linguistic data, such as Matthewson (2004), emphasize that they are a tool to be used with caution and under the observance of a strict methodology. The risks are that a consultant will reject as ungrammatical something that might well occur in natural speech, but that for any number of reasons (e.g., the linguist's unexpressed expectations, the wrong pragmatic context, etc.) does not immediately seem felicitous to the consultant; or that the consultant may accept as grammatical, again for any number of reasons (e.g., the linguist's unexpressed expectations, the consultant's wishing to avoid embarrassing the researcher by rejecting the researcher's sentence, influence from the metalanguage), a sentence that might not be acceptable in the natural usage of the language. MacSwan justifies his use of grammaticality judgments as linguistic data, stating that they are necessary in order to obtain negative evidence crucial for his purpose of showing which kinds of codeswitching are allowed and which are not. However, finding the basic word order of a linguistic variety does not require negative evidence, but only a large corpus of linguistic data, and the patience to analyze it with attention to pragmatic as well as grammatical phenomena. After all, if confronted with an OVS sentence separated from its discourse context, Hueyapan speakers might also find it unnatural, even if they would later produce it in unmonitored discourse. All this suggests that MacSwan's consultants' grammaticality judgments should only be accepted with extreme caution, and never as the last word about syntactic structures in Southeast Puebla Nahuatl.

A further problem arises with the judgments of the phrases including the Spanish loanword kada. Matthewson gives the following examples of words about which one should be particularly cautious in elicitation.

Other examples are the English universal quantifiers every, each, and all.... These items have subtly different meanings that naïve speakers are never able to articulate precisely. Yet students frequently assert with confidence that a certain lexical item in their own native language corresponds to each, while another one corresponds to all. On closer examination, it has always turned out, in my experience, that the supposed 'each' or 'all' items do not have exactly the meaning or distribution of English each or all. [2004:383-84]

The supposed Nahuatl word for 'every', kada, is exactly the word used by MacSwan as the magic bullet in his proof that true quantifiers exist in the Nahuatl variety he studies. If he has conducted the kind of thorough semantic survey of the use of kada in the language that is recommended by Matthewson, then he does not mention that in the article; the conclusion that kada is in fact a "true quantifier" in the language rests on his word and the grammaticality judgments of his consultants. The reader of MacSwan's article is also left uncertain how far the Spanish word kada is integrated into the grammatical system of Nahuatl: whether it is a case of codeswitching that may be governed by other syntactic rules than those of "pure" Nahuatl syntax; whether the quantifier 
kada in fact occurs in natural Southeast Puebla Nahuatl discourse or whether the examples are constructed by MacSwan and merely judged to be grammatical by his codeswitching informants; and, supposing the word is in fact fully integrated into Southeast Puebla Nahuatl, whether there are any restrictions on its usage in the language, such as the preference for it being used in the phrase kada se in Hueyapan Nahuatl. In short, kada provides only very weak grounds for arguing that noun phrases are not adjuncts in Southeast Puebla Nahuatl, that Southeast Puela Nahuatl is not nonconfigurational, and that the Polysynthesis Parameter does not exist.

Furthermore, there are more specific problems with the sentences used by MacSwan in his judgment tasks. First, he has constructed examples with the pronoun ne 'I' functioning as subject. In Nahuan languages, pronouns are known to be typically used only for ascribing pragmatic emphasis such as focus or contrast to sentence participants. Launey in fact labels this class of words "emphatic pronouns" (1992:41). This is also the case in my data, where pronoun use correlates highly with pragmatic focus (except for one speaker who is Spanish-dominant and uses the pronouns as pragmatically unmarked anaphora). Hence, in several Nahuan languages pronouns tend to occur dislocated to the left more frequently than other nouns. Furthermore, one of the pronouns in MacSwan's examples is a first person pronoun, which is inherently more topical than a third person pronoun in the majority of the languages of the world. This means that the sentences used by MacSwan for determining basic word order are not good examples of pragmatically unmarked sentences in Nahuatl or in general. For example, the reason that example (20) was judged ungrammatical might well be that there are two noun phrases vying for the status of focus in the sentence: the fronted object in Maria and the emphatic pronoun ne. Had MacSwan constructed a sentence without emphatic pronouns, or one with two third person singular participants, such as in Maria niktlasojtla 'Maria, I love her', or in Maria, ye kitlasojtla 'Maria, her he loves', he might well have found that the fronted object could have been judged to be grammatical.

The second kind of data used by MacSwan is written texts. Nahuatl is not used as a written language by the large majority of Nahuatl-speaking communities and writing is nearly always something learned through Spanish for use in Spanish. Those who do write in Nahuatl apply what they have learned about writing in Spanish. MacSwan (1997:124) mentions that residents of the town from which his consultants come receive no instruction in writing Nahuatl, and only 68 percent of inhabitants can read and write in Spanish. It is a well-known phenomenon that when writing in a language that is not usually used as a written language a writer may unconsciously transfer structures from the language that he or she usually writes in to the otherwise unwritten language. Mithun (2006:298-305) describes how in their writings bilingual authors of didactic grammars of Mohawk use a syntax more similar to English syntax than to that of spoken Mohawk. For example, this kind of written Mohawk uses a far larger 
number of free noun phrases and a more fixed constituent order than is usual for spoken Mohawk. MacSwan at one point does raise the question of how much reliance should be placed on his consultants' written texts in determining word order, writing "Taken alone, it may be that statistical information of this sort should not be fully trusted. After all, a similar analysis of English novels might make English out to be an OSV language" (1998:107). But he maintains that the analysis of written texts combined with the equally problematic sentence judgments constitute strong evidence of a fixed word order in the variety of Nahuatl that he is studying. I, however, am not convinced and I would not be surprised if a study of word order in spoken Southeast Puebla Nahuatl were to yield results more similar to mine.

The greatest problem for MacSwan's conclusions, however, is the apparent uncertainty as to exactly which language he is making claims about. At times he draws conclusions about Southeast Puebla Nahuatl, as, for example, when he writes, "These facts suggest that the basic clause structure of Southeast Puebla Nahuatl is not significantly different from that of English, Spanish or other well-studied languages" (1998:104). At other times, he extends his conclusions to Nahuatl without any qualification; for example, he writes: "I claim that Nahuatl, in this respect, is not essentially different from English or other wellstudied languages" (1998:103). This could just be imprecise use of terminology, but it raises the question of how far conclusions can be extended while still enjoying the support of the data. And consequently one may ask: Which variety of Nahuatl is MacSwan really studying?

In his dissertation (1997:123-27), MacSwan describes in detail the linguistic backgrounds of three of his consultants; however, these are not the consultants who wrote the texts used for word order analysis, but only those used for naturalistic data and sentence judgment tasks. The only data given about the five authors of the narratives are their names and their hometown-San Sebastián Zinacatepec. However, we can deduce from the information that MacSwan gives about the community of San Sebastián that the writers are probably not Nahuatl monolinguals and that they are likely to have acquired literacy through schooling in Spanish rather than Nahuatl. In accordance with the observations of Foley (2002), they are thus likely to have a relatively high degree of metalinguistic awareness and, consequently, are likely to have a greater tendency to display traits of literacy, such as more noun phrase participants per clause, a more integrated narrative structure, and less reliance on speech acts and personal involvement. As observed by Mithun (2006), they are also likely to unconsciously introduce syntactic features of their language of literacy, Spanish, when composing written texts in their usually unwritten languages. In this case, such features might well include a fairly rigid SVO word order and more noun phrase participants.

MacSwan describes how the three informants who provided grammaticality judgments were selected for the study. His dissertation treated the topic of 
intrasentential codeswitching from a Minimalist perspective and his consultants were selected to be "balanced" bilinguals (i.e., not predominant speakers of one of their languages) and to be positively disposed towards codeswitching. His data comes principally from three consultants all of whom are males between the ages of twenty-four and twenty-six from the town of San Sebastián Zinacatepec in Puebla's Tehuacán Valley. Two of these consultants, a pair of close friends and brothers-in-law, were the principal source of data since they were most comfortable with codeswitching, whereas the third had grown up in a monolingual Nahuatl-speaking home and was uncomfortable with speaking in this way because he is "not often in a conversational situation with bilinguals which is informal enough to allow code switching" (1998:125). A fourth consultant was a thirty-six-year-old male from San Juán Tetelcingo, Guerrero, with an advanced education in business and a job as a Nahuatl teacher, but MacSwan mentions that since he had a negative attitude towards codeswitching, the data obtained from him was not used. This means that the sentence judgments were made by Nahuatl speakers who were not only fully bilingual and literate, but also speakers that were positively disposed towards introducing Spanish structures into Nahuatl, a profile which, as evidenced from the testimony of the third informant, does not extend to the general community of San Sebastián Zinacatepec.

Can we be sure that the data obtained from these seven consultants is representative for Southeast Puebla Nahuatl as a whole? The southeast Puebla area is the home of some 130,000 Nahuatl speakers distributed among dozens of communities (Gordon 2005), and shows considerable dialectal diversity, as can be seen in dialect studies of the area (Hasler Hangert 1996). Can we then be sure that the data are representative for Nahuatl of San Sebastián Zinacatepec as a whole? Zinacatepec is a town with approximately 4,500 Nahuatl speakers of all ages, among them 271 monolinguals, and 2,500 non-Nahuatl speakers (MacSwan 1998:124). The answer to both questions is clearly "no." The surprising degree of linguistic variation that can be found even in small coherent speech communities is well documented (Dorian 2001). San Sebastián is obviously not a very homogeneous community, and one would expect interspeaker variation; it seems improbable that one would be able to document such variation with only seven consultants of similar backgrounds. The data provide even less support for conclusions about Nahuatl in general. Nahuatl is a dialect continuum with more than a million speakers and dozens of distinct dialects, many of which are mutually unintelligible.

Can we be sure that the material from Hueyapan is entirely representative of the entire speech community? No, but it must be considered much more so, since the number and age range of consultants, as well as the number of analyzed sentences, is greater, and because the data are derived from a more natural context with near-minimal contamination by the linguist and by the metalanguage. 
As shown in my study, the syntax of younger, fully bilingual speakers exhibits quite different properties from that of speakers who are Nahuatl dominant. The differences consist mainly in a more fixed word order, and in more frequent (or considerably less frequent) use of free noun phrase constituents. If I had limited my investigation to three consultants in the youngest third of the age spectrum I might quite possibly have arrived at conclusions similar to MacSwan's about Hueyapan Nahuatl syntax, and, in doing so, I would have missed important information about how Nahuatl is actually spoken in the community.

Finally, it may not be entirely inappropriate to raise the question of the unconscious influence of theoretical orientations on a researcher's interpretation of his or her data. The orientation of the Minimalist Program within the generative tradition, to which MacSwan adheres, encourages adherents to consider the syntax of all languages to be derivable from Universal Grammar. A theoretical persuasion of this kind may incline researchers operating within this paradigm, perhaps more than those working within some others, to minimize differences among languages and to find, as MacSwan does, that even an unrelated language such as Nahuatl is "not essentially different from English or Spanish" (1998:103) in certain respects. This is not to suggest that MacSwan (or others researchers of equally strong and diverse persuasions) would manipulate their data to achieve a satisfactorily congruent outcome, but only that all of us are naturally gratified with findings that apparently confirm our theoretical expectations and may, as a consequence, question their methodological sturdiness less extensively than we otherwise might.

In short, while it cannot be concluded that the Nahuatl of San Sebastián Zinacatepec does not have fixed SVO word order, it is obvious that studies of a larger variety of speakers and textual genres will be required to draw conclusions about the word order of San Sebastián Zinacatepec and of Southeast Puebla Nahuatl in general.

5. Conclusions. As noted in section 1, the purpose of the present article is not to vindicate Baker's Polysynthesis Parameter, but to draw attention to methodological concerns in the study of the syntax of endangered and less studied languages. A second purpose, of equal importance, the present article provides a description of word order in a Nahuan language based on a corpus that, while perhaps not fully representative of all the speakers and speech genres of the linguistic community of Hueyapan, must be seen as more naturalistic and providing broader coverage than MacSwan's data. Lastly, it must be concluded that the data from Hueyapan Nahuatl add one more language to the list of languages that exhibit both adherence to the two basic rules of the Polysynthesis Parameter, and the syntactic properties predicted by Baker for polysynthetic languages (in his sense of the term "polysynthetic"). I will leave the question of whether or not polysynthesis exists as a macroparameter to other scholars. 


\section{Notes}

Acknowledgments. The present article was written in 2009 while the author was supported by a generous grant from Stud. Mag. Per Slomanns Legat. It is a substantial reworking of parts of Hansen (2007), including material from subsequent periods of fieldwork. The article has benefited from critical commentary by Una Canger and Nancy Dorian, although the author accepts sole responsibility for all flaws and errors remaining in the manuscript.

Abbreviations. The abbreviations used in this article are as follows: ABS =absolutive; APPL = applicative; $\mathrm{DEF}=$ definite; DIR = directional; DIST = distal; IMP = imperative; IN = particle in (used in examples from MacSwan); LOC = location; $\mathrm{NP}=$ noun phrase; $\mathrm{O}$ =object (as syntactic constituent); OBJ = object (prefix on verb); PL = plural; POSS = possessive; $\mathrm{PRF}=$ perfective; $\mathrm{PST}=$ past $\mathrm{RDPL}=$ reduplication; $\mathrm{REFL}=$ reflexive; $\mathrm{S}=$ subject (as syntactic constituent); SBJ = subject (prefix on verb); SG =singular; STAT = stative; V = verb.

Transcription. In this article, my data are transcribed using the following conventions for Hueyapan Nahuatl: $x=\left[\int\right], t z=[\overline{\mathrm{ts}}], c h=[\overline{\mathrm{t}}], t l=[\overline{\mathrm{tl}}], y=[\mathrm{j}], \bar{a}=[\mathrm{a}:], \bar{e}=[\mathrm{e}:], \bar{\imath}=$ [i:], $\bar{o}=$ [o:]; all other symbols are equivalent to their IPA values. MacSwan's transcription uses $j=[\mathrm{h}]$ and does not mark vowel length (perhaps it does not exist in the variety he studied); otherwise, his conventions are the same.

1. In Hueyapan Nahuatl predicates can be either verbal or nominal. In this article, I utilize the abbreviation "V" to refer to predicates of either kind and the term "fronted" to mean "appearing in a position to the left of the predicate."

2. Verbs have no prefix for third person subjects; this is shown in examples by a null morpheme $\varnothing$ -

3. The word chika is an unanalyzable particle that functions as a preposition meaning "with, and" when describing a pair of two persons (the dog is clearly personalized in the story). I have not seen this word reported for other dialects.

4. There is even an example of secondary/indirect objects being fronted.

5. Some investigators have suggested that relational nouns are becoming prepositions in some Nahuatl dialects and no longer agree with their possessors (Flores Farfán 2001; Hill and Hill 1986). The evidence presented for this claim is nearly always relational nouns without the third person possessive prefix. I do not accept this as evidence that relational nouns have become prepositions, since, in my Hueyapan Nahuatl data, relational nouns always agree with their possessor if the possessor is not third person. This means that the third person possessive prefix has merely been converted to $\emptyset$ - by analogy to the subject prefix. I suspect this is also the case in the dialects studied by Flores Farfán (1999) and Hill and Hill (1986), since I have never seen them give an example of a relational noun that did not overtly agree with a first or second person possessor.

6. Baker considers all of these constructions as discontinuous, because they contain "a determiner-like element split off from the NP it is associated with semantically" (1996:138).

7. Examples from MacSwan (1998) retain the original translations and morphological segmentation of that work, but the morpheme-by-morpheme glossing has been changed to conform to the Leipzig standard used in the rest of the article.

\section{References}

Baker, Mark C.

1996 The Polysynthesis Parameter. New York: Oxford University Press. 
Beller, Richard, and Patricia Beller

1979 Huasteca Nahuatl. In Modern Aztec Grammatical Sketches, edited by Ronald W. Langacker, 199-306. Dallas: Summer Institute of Linguistics.

Brockway, Earl

1979 North Puebla Nahuatl. In Modern Aztec Grammatical Sketches, edited by Ronald W. Langacker, 141-98. Dallas: Summer Institute of Linguistics.

Canger, Una

1988 Nahuatl Dialectology: A Survey and Some Suggestions. International Journal of American Linguistics 54(1):28-72.

Chafe, Wallace

1982 Integration and Involvement in Speaking, Writing, and Oral Literature. In Spoken and Written Language: Exploring Orality and Literacy, edited by Deborah Tannen, 35-53. Norwood, N.J.: Ablex.

Dimmendaal, Gerrit

2001 Places and People: Field Sites and Informants. In Linguistic Fieldwork, edited by Paul Newman and Martha Ratliff, 55-75. Cambridge: Cambridge

Dorian, Nancy C. University Press.

2001 Surprises in Sutherland: Linguistic Variability Amidst Social Uniformity. In Linguistic Fieldwork, edited by Paul Newman and Martha Ratliff, 133-51. Cambridge: Cambridge University Press.

Flores Farfán, José Antonio

1999 Cuatreros somos y toindioma hablamos: contactos y conflictos entre el náhuatl y el español en el sur de México. Tlalpán, D.F.: Centro de Investigaciones y Estudios Superiores en Antropología Social.

Foley, William A.

2002 Genre, Register and Language Documentation in Literate and Preliterate Communities. In Language Documentation and Description. Vol. 1, edited by Peter K. Austin, 85-98. London: Hans Rausing Endangered Language Project.

Golumbia, David

2004 The Interpretation of Nonconfigurationality. Language and Communication: An Interdisciplinary Journal 24 (1):1-22.

Gordon, Raymond G., Jr., ed

2005 Ethnologue: Languages of the World. 15th ed. Dallas: SIL International. http://www.ethnologue.com.

Hansen, Magnus Pharao

2007 Tamasolin kānin tikah? Lille frø Hvor er du? En undersøgelse af Polysyntese i Hueyapan Nahuatl. M.A. thesis, University of Copenhagen.

Harris, Zellig S., and C. F. Voegelin

1953 Eliciting in Linguistics. Southwestern Journal of Anthropology 9:59-75.

Hasler Hangert, Andrés Teyolotzin

1996 El náhuatl de Tehuacán-Zongolica. Mexico City: Centro de Investigaciones y Estudios Superiores en Antropología Social.

Hill, Jane H., and Kenneth C. Hill

1986 Speaking Mexicano: Dynamics of Syncretic Language in Central Mexico. Tucson: University of Arizona Press.

Labov, William

1972 Some Principles of Linguistic Methodology. Language in Society 1:97-120.

Lambrecht, Knud

1994 Information Structure and Sentence Form: Topic, Focus, and the Mental 
Representations of Discourse Referents. Cambridge: Cambridge University Press.

Lastra de Suárez, Yolanda

1986 Las áreas dialectales del náhuatl moderno. Serie antropológica, no. 62. Ciudad Universitaria, México, D.F.: Universidad Nacional Autónoma de México, Instituto de Investigaciones Antropológica.

Launey, Michel

1992 Introducción a la lengua y a la literatura Náhuatl. Mexico City: Instituto de Investigaciones Antropológicas, Universidad Nacional Autónoma de México. (The French original appeared in 1979.)

1999 Compound Nouns vs. Incorporation in Classical Nahuatl. In Problems of Polysynthesis, edited by Nicholas Evans and Hans Jürgen Sasse, 113-34.

MacSwan, Jeffrey Berlin: Akademie Verlag.

1997 A Minimalist Approach to Intrasentential Code Switching: SpanishNahuatl Bilingualism in Central Mexico. Ph.D. diss., University of California, Los Angeles.

1998 The Argument Status of NPs in Southeast Puebla Nahuatl: Comments on the Polysynthesis Parameter. Southwest Journal of Linguistics 17(2): 101-14.

Matthewson, Lisa

2004 On the Methodology of Semantic Fieldwork. International Journal of American Linguistics 70(4):369-415.

Mayer, Mercer

1969 Frog, Where Are You? New York: Dial Press.

Mithun, Marianne

2001 Who Shapes the Record: The Speaker and the Linguist. In Linguistic Fieldwork, edited by Paul Newman and Martha Ratliff, 34-54. Cambridge: Cambridge University Press.

2006 Grammars and the Community. Studies in Language 30(2):281-306.

Schütze, Carson T.

1996 The Empirical Base of Linguistics: Grammaticality Judgments and LinSischo, William guistic Methodology. Chicago: University of Chicago Press.

1979 Michoacán Nahual. In Modern Aztec Grammatical Sketches, edited by Ronald W. Langacker, 307-80. Dallas: Summer Institute of Linguistics.

Tuggy, David

1979 Tetelcingo Nahuatl. In Modern Aztec Grammatical Sketches, edited by Ronald W. Langacker, 1-140. Dallas: Summer Institute of Linguistics. 